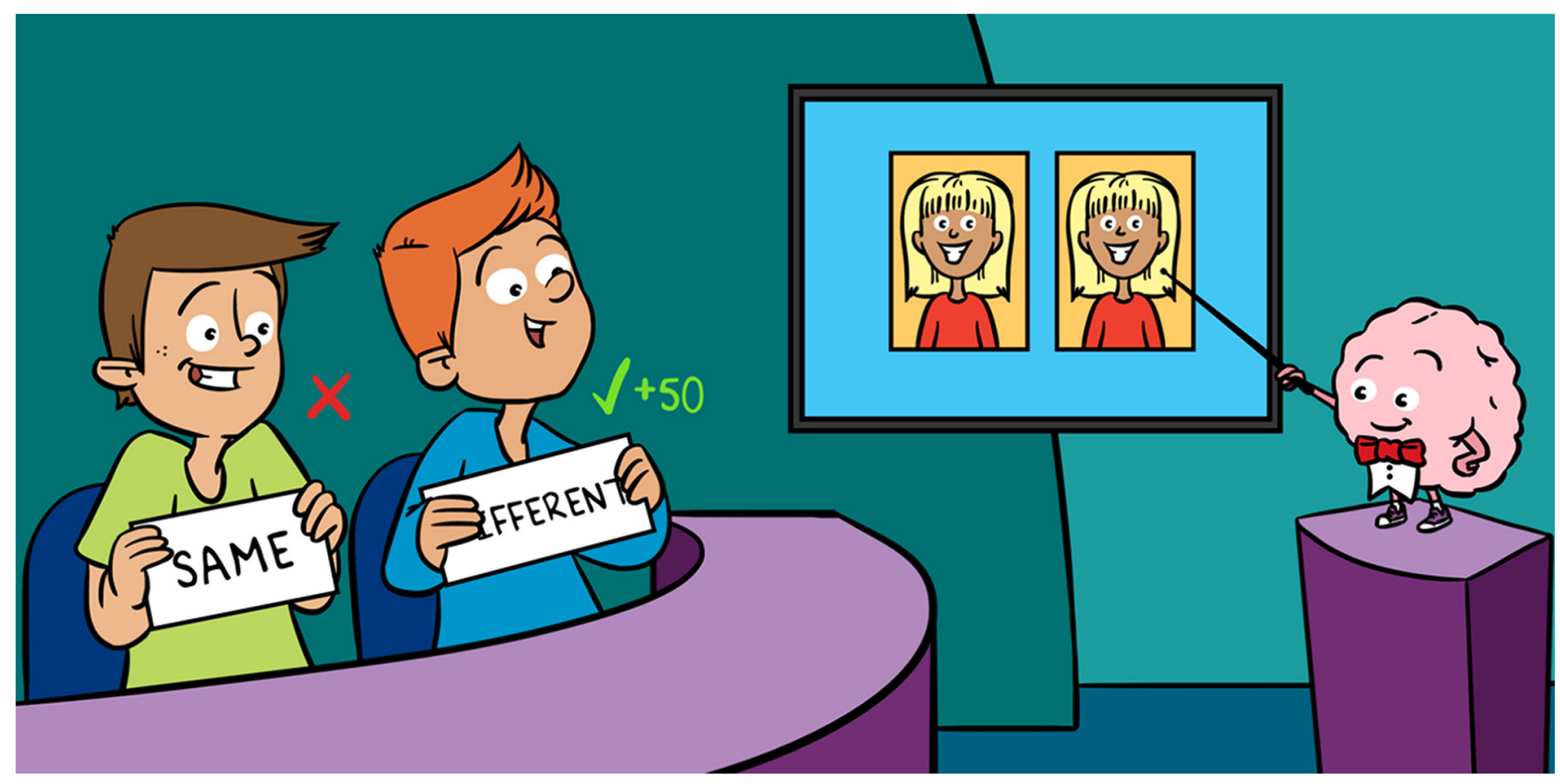

\title{
WHY ARE SOME PEOPLE BETTER AT RECOGNISING FACES THAN OTHERS?
}

\section{Karen Lander ${ }^{1 *}$ and Markus Bindemann ${ }^{2}$}

${ }^{1}$ Division of Neuroscience and Experimental Psychology, University of Manchester, Manchester, United Kingdom

${ }^{2}$ School of Psychology, University of Kent, Canterbury, United Kingdom

\section{YOUNG REVIEWERS:}

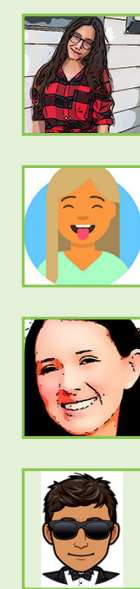

ELIF

AGE: 16

JORDYN

AGE: 16

LAURA

AGE: 15

LUCAS

AGE: 16
Imagine you lose sight of your friends (or parents) for a moment while you are out at the park. You glance around and then spot them in the distance. You easily pick them out from all the other people in the park and you correctly identify them. This process is called familiar face recognition. For most of us, this process seems easy and generally people are good at recognising familiar faces. However, a few people really struggle to recognise the people around them. Other people are "super-recognisers" who have an extraordinary ability to recognise faces very accurately. How good are you at recognising faces? In this article, we outline why some people are better (or worse) at recognising faces and explore the possible importance of brain differences, mental processes, and personality in this ability. 
Figure 1

Individuals vary in their ability to recognise faces. The normal range of performance in face-recognition ability shows that most people have an intermediate level of this ability. A small number of people are extremely poor at recognising faces; a disorder called prosopagnosia. On the other end of the spectrum, a small number of people are extremely good at recognising faces and are called super-recognisers.

1 If you want to learn more about super-recognisers and see if you are one, check out https://www. superrecognisers. com/

NORMAL RANGE OF PERFORMANCE

The range of scores obtained by people on tests of a particular task or skill (in our case, face recognition).

TEMPORAL LOBES

One of the four main regions of the brain.

There is a temporal lobe on each side of the brain, located close to the ears. This area of the brain is involved in visual memory, language understanding and emotion processing.

PROSOPAGNOSIA

A neurological condition that is characterised by the inability to recognise familiar faces.

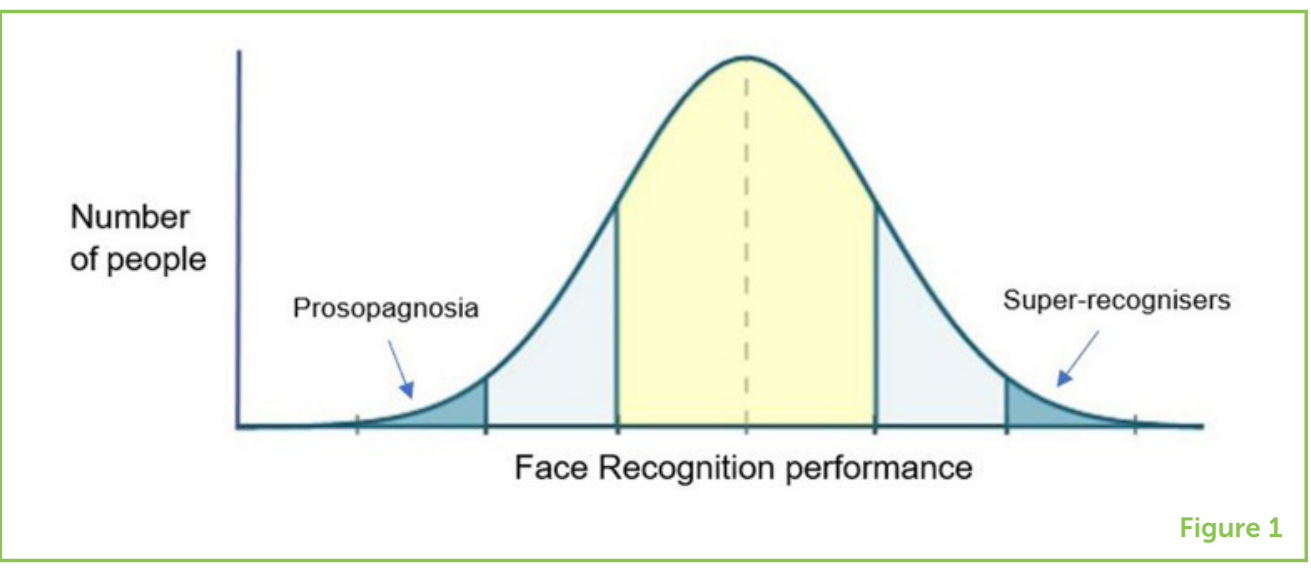

\section{INTRODUCTION}

Most of us can recognise the people around us, our friends, family, and teachers. By the time we are adults, most of us can accurately recognise hundreds of different people. This ability is shaped by our social environment. For example, people generally find it easier to recognise faces from the same racial and age groups as themselves. Why is face recognition important? It helps us to act the right way in social situations, for example sharing a joke with a friend and paying attention to the teacher, rather than the other way around! Recent research has focused on individual differences in face-recognition ability. Some people are particularly poor at recognising faces while other people, nicknamed super-recognisers, can very accurately remember and recognise faces. Super-recognisers have even helped the police to identify suspects involved in crimes! ${ }^{1}$

Most of us are between these extremes-we are not really bad at recognising faces, but we are not super good either. Instead, we are within the middle part of the normal range of performance (Figure 1). For example, in a study in which participants were asked if two pictures show the same person or different people, performance ranged from 62 to 100\% correct across individual observers [1]. Why are some people better at recognising faces?

\section{BRAIN DIFFERENCES}

Brain differences between individuals are one possible reason for differences in the ability to recognise faces. Maybe people who are good at recognising faces have brains that are bigger, more connected, or somehow working better than the brains of people who are not so good at recognising faces? Several brain areas important for face recognition are found in the temporal lobes, which are located at the sides of the brain, above the ears (Figure 2). We know that people with damage to these brain areas may have a disorder called prosopagnosia. Prosopagnosia has been called "face blindness" and it is characterised by difficulty recognising familiar faces. 
Figure 2

The temporal lobes are situated above the ears. They are involved in face recognition ${ }^{2}$. This image was made out of, or made from, content published in a BodyParts3D/

Anatomography web site (c) The Database Center for Life Science licensed under Creative Commons Attribution 2.1 Japan.

2 If you want to find out about the function and location of the fusiform face area (FFA) then please see https://en. wikipedia.org/ wiki/Fusiform_ face_area

\section{COGNITIVE \\ PROCESSING}

The mental processes (things that go on in our heads) that are involved in gaining knowledge and understanding things. These include perception, encoding, and memory.

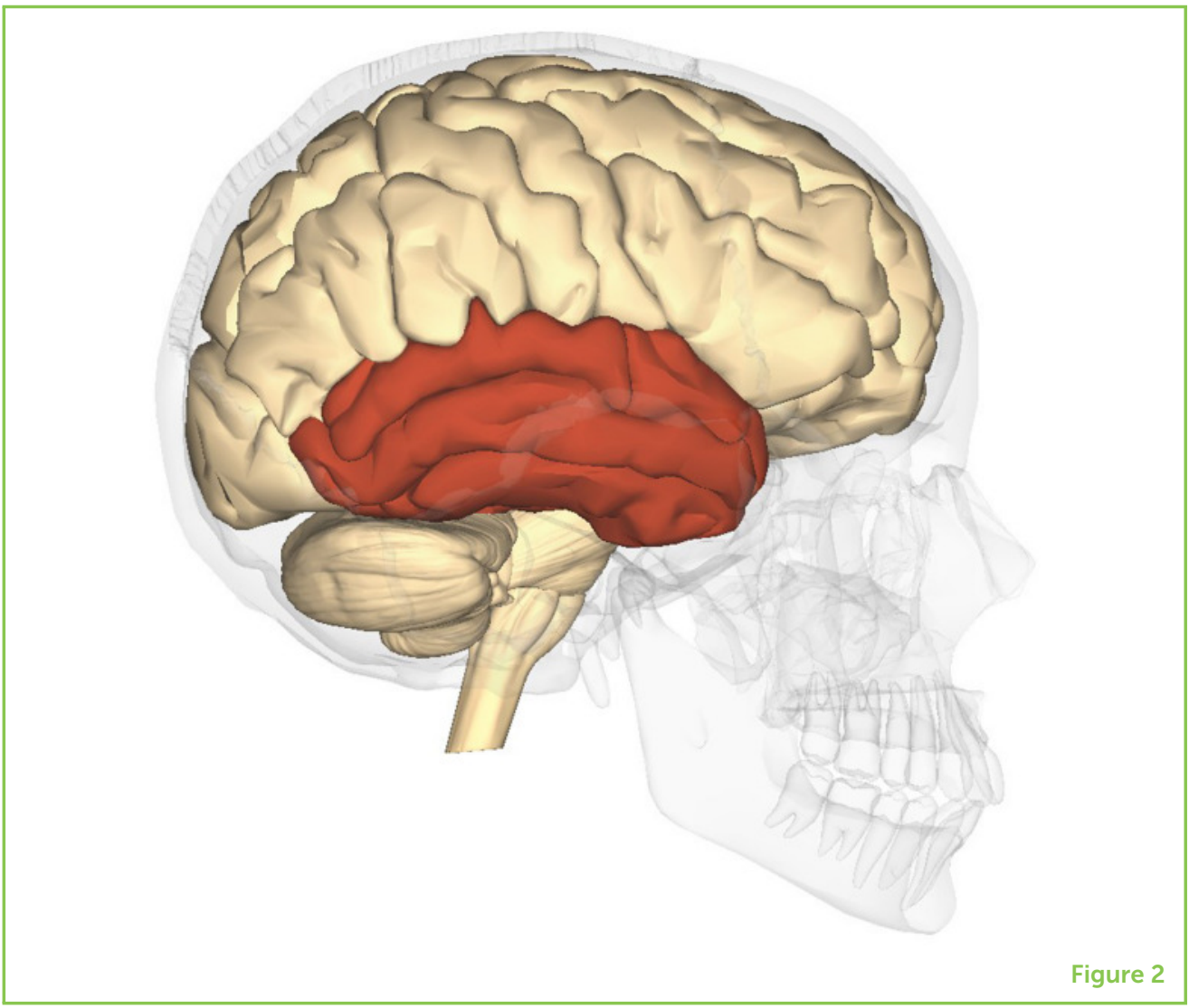

Do people who are good at recognising faces have face-recognition areas in their brains that are more developed than those of other people? The short answer is that we are not really sure. Some work has suggested that a higher level of activation in these brain areas is related to better face recognition [2]. Other researchers have found that people with very poor face-recognition abilities may have fewer connexions between the various face-related areas of the brain [3]. Overall, more research is needed to determine whether differences in brain activation and connectivity play a role in how good we are at recognising faces.

\section{COGNITIVE PROCESSING}

A second possible reason for individual differences in face recognition is that this ability is related to factors like intelligence or memory-these are both types of cognitive processing. Cognitive processing means the mental processes (things that go on in our heads) that are involved in gaining knowledge and understanding. Maybe people who are more intelligent are better at recognising faces? Research on this topic asks volunteers to take part in an intelligence test and a face-recognition task. Results from these tasks are then compared and, generally, no strong relationship is found. This means that it is not the case that the cleverest people are always the best at recognising faces. 


\section{Figure 3}

To test the capacity of visual memory, a memory game such as the one shown was used. Participants looked at the objects for a short time and were then asked to remember them when they were covered up.

\section{VISUAL}

\section{PROCESSING}

\section{ABILITY}

The brain's ability to use and interpret information from things we see in the world around us.
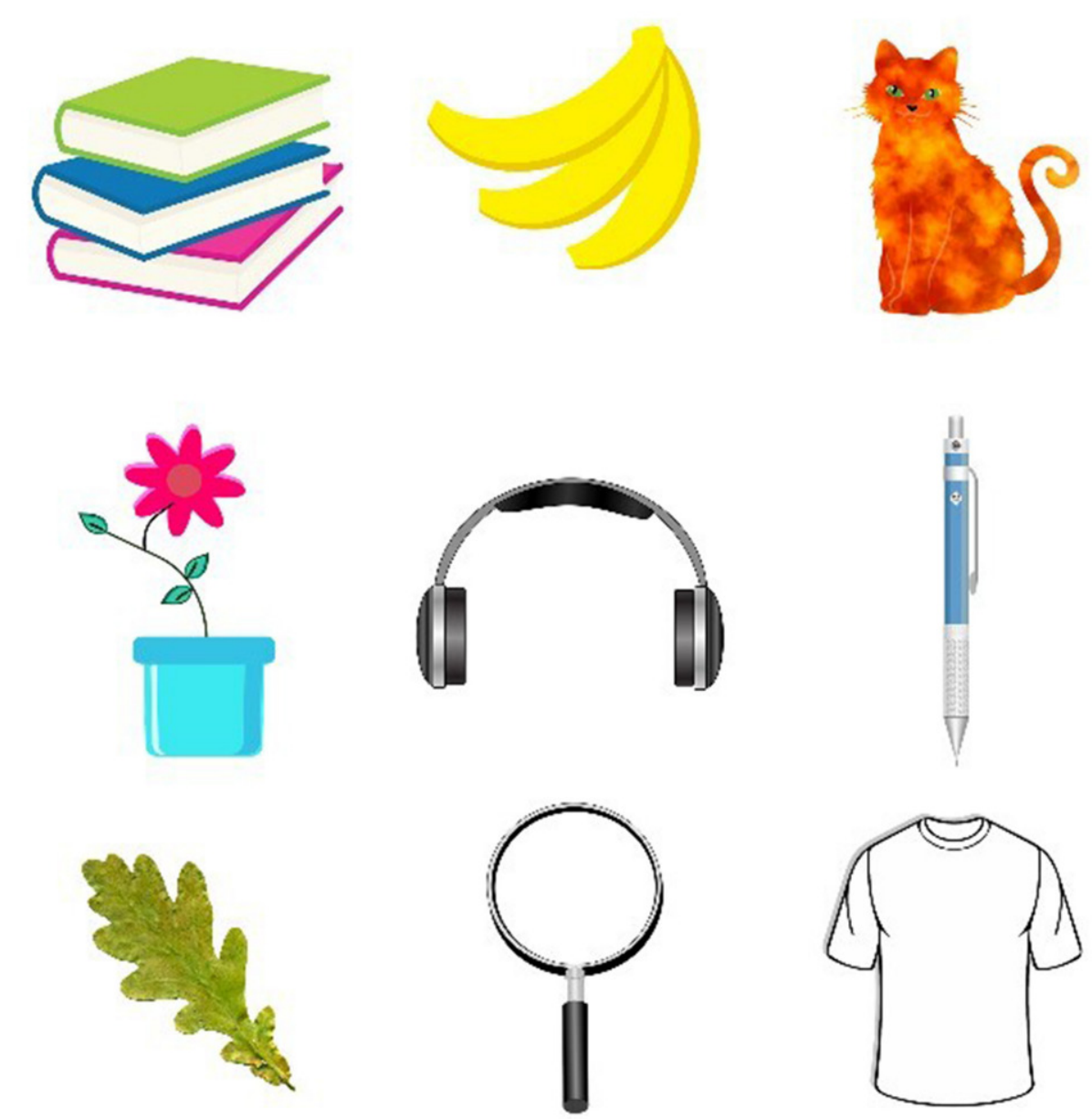

Figure 3

There does seem to be a relationship between face recognition and visual processing ability, which is the brain's ability to understand and remember things that we see. For example, research found that face-recognition performance was related to visual short-term memory [4]. You might have taken part in a visual memory game yourself. You see a group of objects-for example, pictures of foods, clothes, instruments, animals, plants, vehicles, or other things. These objects are shown briefly, usually only for a few seconds, and then covered up. Your task is to remember as many of the objects as possible (Figure 3). The number you remember is a measure of your visual short-term memory. Researchers found that the results of this kind of memory test were related to face-recognition ability-as one ability increased, so did the other.

\section{PERSONALITY AND SOCIAL INTERACTION}

It is also possible that how good people are at recognising faces is linked to their personalities or levels of social interaction. Perhaps people who are more interested in meeting and talking with other people are more practised at recognising faces and are better 


\section{EMPATHY}

The ability to understand and share the feelings of other people. at recognising them. Alternatively, people who are not good at recognising faces may avoid people so that they are not embarrassed by their inability to recognise familiar faces. What do you think?

Research has shown that people who are better at thinking about and sharing the emotions of others - a trait called empathy-are better at recognising faces. Volunteers were asked to answer a series of questions to measure their empathy and they also participated in a face-recognition task. Results showed that the "high empathy" group performed better on the face-recognition task compared with the "low empathy" group [5]. Research has also shown that people who are worried and anxious in social situations are worse at recognising faces compared with more confident people [6]. People who are more outgoing and sociable (extraverted) are better at recognising faces than people who are more introverted [7]. There is also some evidence that a tendency toward negative feelings has a negative influence on face recognition. What kind of person are you? Do you like interacting with the people around you, or are you more reserved?

\section{CAN FACE-RECOGNITION ABILITY CHANGE?}

Can the ability to recognise faces change with time? Are there things we can do to get better at recognising faces? It is thought that the ability to accurately recognise faces improves with age, starting at about 5 years old until adulthood, with a dip possible during early adolescence. There is also a decrease in face-recognition ability from about age 30 onwards, as we age.

There are many skills we can learn by practising them-is face recognition one of these skills? Researchers are still not sure. It may be that the more people we meet, the better we are at face recognition. However, simply increasing contact with faces does not necessarily improve performance. For example, one study showed that nursery workers and school teachers, who see a lot of children's faces, were no better at identifying faces than were people with little experience with children [8].

People with prosopagnosia often say that they struggle to recognise their classmates and form friendships-can anything be done to help them? Some people with prosopagnosia use coping strategies (tricks to help them recognise people), including details of people's hairstyles or clothing. But training people to be better at face recognition is difficult, and training prosopagnosics does not usually produce any lasting improvement in face recognition. We also know that many passport control officers and police officers find it challenging to recognise faces, and training does not improve their recognition ability. 


\section{CONCLUSION}

We are surrounded by people, and recognising their faces allows us to form friendships, interact appropriately, and work or play together. However, we are not all equally good at recognising faces. Individual differences in the ability to recognise faces might be related to differences in our brains, for example, how much some brain areas are activated when we see faces and how well certain brain areas work together. These differences might also be related to our visual processing abilities, or aspects of our personalities, such as how outgoing and sociable we are. Understanding these individual differences is important. Some jobs, such as passport officers at airports and borders or facial examiners working for the police require a high level of face recognition, and it does not seem that this ability can be easily improved with practise. It might be better to select people who are naturally good at recognising faces for these jobs. Maybe this could be you!

\section{ACKNOWLEDGEMENTS}

Many thanks to our reviewers and also to 17-year-old reviewer Angelina. Your comments were very useful in developing the article.

\section{ORIGINAL ARTICLE}

Lander, K., Bruce, V., and Bindemann, M. 2018. Use-inspired basic research on individual differences in face identification: implications for criminal investigation and security. Cogn Res Princ Implic. 3:26. doi: 10.1186/s41235-018-0115-6

\section{REFERENCES}

1. Burton, A. M., White, D., and McNeill, A. 2010. The Glasgow Face Matching Test. Behav Res Methods. 42:286-91. doi: 10.3758/BRM.42.1.286

2. Rotshtein, P., Geng, J. J., Driver, J., and Dolan, R. J. 2007. Role of features and second-order spatial relations in face discrimination, face recognition, and individual face skills: Behavioral and functional magnetic resonance imaging data. J Cogn Neurosci. 19:1435-52. doi: 10.1162/jocn.2007.19.9.1435

3. Rosenthal, G., Tanzer, M., Simony, E., Hasson, U., Behrman, M., and Avidan, G. 2017. Altered topology of neural circuits in congenital prosopagnosia. Elife. 6:e25069. doi: 10.7554/eLife.25069

4. Megreya, A. M., and Burton, A. M. 2006. Unfamiliar faces are not faces: evidence from a matching task. Mem Cogn. 34:865-76. doi: 10.3758/bf03193433

5. Bate, S., Parris, B., Haslam, C., and Kay, J. 2010. Socio-emotional functioning and face recognition ability in the normal population. Pers Indiv Diff. 48:239-42. doi: 10.1016/j.paid.2009.10.005 
6. Davis, J. M., McKone, E., Dennett, H., O'Connor, K. B., O'Kearney, R., and Palermo, R. 2011. Individual differences in the ability to recognise facial identity are associated with social anxiety. PLOS ONE. 6:e28800. doi: 10.1371/journal.pone.0028800

7. Lander, K., and Poyarekar, S. 2015. Famous face recognition, face matching, and extraversion. Q J Exp Psychol. 68:1769-76. doi: 10.1080/17470218.2014.988737

8. Bate, S., Bennetts, R., Murray, E., and Portch, E. 2020. Enhanced matching of children's faces in "super-recognisers" but not high-contact controls. i-Perception. 11:2041669520944420. doi: 10.1177/2041669520944420

SUBMITTED: 21 August 2020; ACCEPTED: 02 September 2021; PUBLISHED ONLINE: 21 October 2021.

EDITED BY: David L. Sheinberg, Brown University, United States

CITATION: Lander K and Bindemann M (2021) Why Are Some People Better at Recognising Faces Than Others? Front. Young Minds 9:597541. doi: 10.3389/frym. 2021.597541

CONFLICT OF INTEREST: The authors declare that the research was conducted in the absence of any commercial or financial relationships that could be construed as a potential conflict of interest.

COPYRIGHT () 2021 Lander and Bindemann. This is an open-access article distributed under the terms of the Creative Commons Attribution License (CC BY). The use, distribution or reproduction in other forums is permitted, provided the original author(s) and the copyright owner(s) are credited and that the original publication in this journal is cited, in accordance with accepted academic practice. No use, distribution or reproduction is permitted which does not comply with these terms.

\section{YOUNG REVIEWERS}
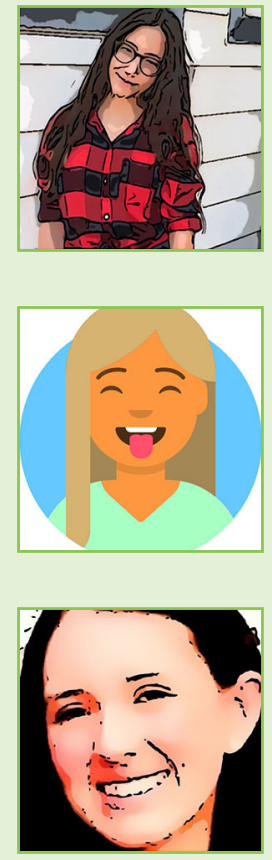

\section{ELIF, AGE: 16}

Hi, I am Elif from Turkey. I am currently a rising junior. I am interested in debate, coding, and music, but mostly the sciences. I plan to pursue a career in physics and biology.

\section{JORDYN, AGE: 16}

Hi! I am extremely interested in all sciences, especially biology, computer science, and astronomy. In my free time I love to read. I also play lacrosse, ski, surf, and love to scuba dive!

\section{LAURA, AGE: 15}

My name is Laura, and I am a ninth grader residing in Charlotte, North Carolina. I am originally from Colombia, and I can fluently speak Spanish. In my free time, 

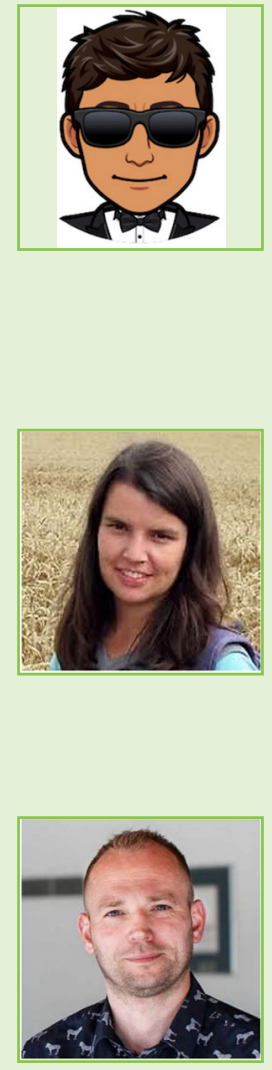

I enjoy whitewater kayaking, but you can also find me playing volleyball with my school team.

\section{LUCAS, AGE: 16}

My name is Lucas, I am a senior at Brookline High School. I speak English, Spanish, and I have been taking Chinese classes since second grade. I enjoy playing video games, watching soccer, and spending time with my family. I am looking forward to begin my college applications this year.

\section{AUTHORS}

\section{KAREN LANDER}

I am a cognitive psychologist working at the University of Manchester. My research is mainly about faces and how we recognise identity. I am particularly interested in the ways that faces move and why some people are better at recognising faces than others. I hope that by studying this topic we will understand more about the importance of face recognition for our everyday lives. I hope you enjoy reading this article. *karen.landeramanchester.ac.uk.

\section{MARKUS BINDEMANN}

I am a cognitive psychologist working in the School of Psychology at the University of Kent in England. I first started learning about psychology when I studied at the Universities of Stirling (B.Sc., 1997-2001) and Glasgow (Ph.D., 2001-2004), and I have now been researching face perception for almost 20 years! I find this research area truly fascinating-it is such a diverse and fast-moving field-and time has just flown by. I hope you will enjoy our article too. 